Introduction

\title{
Introduction: Genomics and philosophy of race
}

\author{
Rasmus Grønfeldt Winther ${ }^{\mathrm{a}, *, 1}$, Roberta L. Millstein ${ }^{\mathrm{b}}$, Rasmus Nielsen ${ }^{\mathrm{c}}$ \\ ${ }^{a}$ Philosophy Department, UC, Santa Cruz, CA, USA \\ ${ }^{\mathrm{b}}$ Philosophy Department, UC, Davis, CA, USA \\ ${ }^{\mathrm{c}}$ Integrative Biology, UC, Berkeley, CA, USA
}

When citing this paper, please use the full journal title Studies in History and Philosophy of Biological and Biomedical Sciences

Philosophy of race has become a multi-faceted subfield of philosophy, drawing on philosophy of biology, metaphysics, philosophy of language, ethics, and political philosophy. Race cuts across disciplinary lines within philosophy. Moreover, disciplines outside philosophy-including population genetics, anthropology, sociology, and education-have much to contribute to discourse about race. A persistent danger of interdisciplinary conversation is that of talking past each other. For instance, scholars in different disciplines have distinct race concepts and use local intellectual machinery to address questions about race. One simple way to address these issues is to have the relevant parties meet each other frequently and repeatedly. But there are some barriers to this strategy. It requires openness, patience, and charity from the participants, and physical proximity is an important consideration.

We realized that our own geographic region-the San Francisco Bay Area-provided the necessary concentration of open, patient, and charitable scholars from many disciplines interested in race. During the 2013-2014 academic year, our group of biologists, philosophers, and social scientists met for two workshops (Stanford, UC Davis) and a public conference (UC Santa Cruz) to discuss a variety of concerns surrounding genomics and race. As a group we shared a commitment to thinking critically about how theoretical population genetics and genomics conceptualize and model certain constructs, such as "populations," which, in turn, are deemed by some to be "races," as theoretical achievements move from a circumscribed biological domain out to the general public. There was of course not complete agreement, but we benefited tremendously from learning from each other. Indeed, we believe the papers in this special issue are evidence that we are now a group of philosophically-informed scientists and scientifically-informed philosophers.

\footnotetext{
* Corresponding author. Philosophy Department, 1156 High St., UCSC, Santa Cruz, CA 95064, USA.

E-mail address: rgw@ucsc.edu (R.G. Winther).

1 URL: http://www.rgwinther.com
}

In the spirit of interdisciplinarity, and in the context of the explicit "talking points" topics presented by one of us (PI Winther) during the Stanford Fall 2013 meeting, organized by Edge and Rosenberg (topics found below), three themes ran through our group discussions and are evident in the papers in this issue:

1. Populations and races (Millstein; Winther, Giordano, Edge, and Nielsen)

2. Examining controversies (Kaplan, Pigliucci, and Banta; Edge and Rosenberg; Spencer)

3. Pragmatics (Lorusso and Bacchini; Donovan)

With respect to the first theme, our group addressed a variety of concepts of "population" and "race" and the implications of findings concerning human populations for our understanding of human races. In her contribution to this issue, Millstein adds an explicit temporal component to her causal interactionist population concept $(2009,2010)$ to help shed light on our understandings of race. In particular, she explores three "puzzles" that illustrate how temporality is crucial when thinking about race. For instance, how can we make sense of concepts of race that incorporate a concept of population if a person can be a member of more than one race at the same time but cannot be part of more than one population at the same time? On the other hand, Winther, Giordano, Edge, and Nielsen distinguish three kinds of populations, which play distinct roles in three research contexts: theory, laboratory, and field. They argue that confusions have arisen from conflations among the three. Each of these papers thus examines a key notion of evolution and ecology, "population," and its complex relationship to a simultaneously narrower and broader concept, "race."

Not surprisingly, discussions surrounding race have produced a number of biological and philosophical controversies, some of them longstanding ones. As a second theme of our special issue, a number of authors analysed some of these controversies. Kaplan, Pigliucci, and Banta examine the dispute between Morton (1849) 
and Gould (1978) over the skull sizes of different folk-races, arguing (contra Lewis et al., 2011) that Gould was right to reject Morton's analysis as inappropriate and misleading, but that he was wrong to believe that a more appropriate analysis was available. Edge and Rosenberg weigh in on the so-called "Lewontin-Edwards debate" (Kaplan \& Winther, 2013; Winther, 2014), a disagreement over the implications of human genetic diversity for human ancestry, by modelling the mapping between genotype and phenotype and showing that when it comes to differences in neutral phenotypes across populations, Lewontin-type single-locus results (Lewontin, 1972) are more informative than Edwards-type multi-locus classification (Edwards, 2003). Spencer turns from these two biological controversies to a philosophical one, with an examination of some philosophical arguments against and for the biological reality of race. He argues that four of the concerns that have been raised stem from implausible assumptions about the relevant meaning of 'race' or the nature of biological realism. Interestingly, Kaplan, Pigliucci, and Banta try to dissolve a controversy; Edge and Rosenberg show that both sides of a controversy are right; and Spencer defends one of two sides of a controversy.

Many important questions concern the "input" (biology) and "output" (social consequences) of theorizing about race, and do not hinge on the metaphysics of race as such. In other words, whether race is real or not, and in which senses, matters mainly in so far as it might make a difference in biomedical, forensic, anthropological, psychological, and political, including identity politics, contexts. Bluntly put, ontology serves pragmatics, giving rise to the third theme. Lorusso and Bacchini argue that differences in race-or, better, in racial self-identification-may be used as proxies for differences in risk-related exposomes and epigenomes in the context of the United States. However, their conclusion comes with a caveat. There is no guarantee that using self-identified races in epidemiology and biomedical research will always be beneficial; positive and negative consequences must be balanced, and risks assessed. Donovan's contribution is also interestingly normative, outlining the necessary subject matter knowledge about race that teachers should possess if they desire to teach about human genetic variation without promoting racialism. This knowledge base is biologically and politically sensitive to the state-of-art on genomics and philosophy of race represented in this volume. Both papers shed light on contexts outside of theoretical biology and philosophy where race has deep impacts, and where constant critical reflection and vigilance is necessary-biomedicine and pedagogy.

We have addressed difficult technical matters both on their own terms and in social contexts, emphasizing pragmatics but also touching on metaphysics at times. Our inter-disciplinary group excelled at dialogue, learning from one another, and experimenting with new perspectives on genomics and philosophy of race. We look forward to continuing that dialogue with the readership of Studies in History and Philosophy of Biological and Biomedical Sciences.

\footnotetext{
“Genomics and Philosophy of Race" Talking Points (2013-2014)

Presented at the Stanford Fall 2013 workshop.

Co-authored by Winther, Millstein, Nielsen, and Michael D. Edge.

This year's topic is "Genomics and Philosophy of Race." Different researchers might work on distinct subsets of the six thematic clusters below, which are neither mutually exclusive nor collectively exhaustive:
}

(1) Concepts of 'Race': What is the relation of 'race' to standard terms and concepts in the biological literature, including ancestry, clade, cluster, ethnicity, group, population, and subspecies? Did these concepts historically replace and realign the post-WW II term 'race'? (UNESCO 1952, Reardon, 2005) For instance, consider the concepts of 'population' and 'metapopulation.' (Millstein, 2010) These concepts seem to play a central but complex role in the studies of the evolution and population structure of Homo sapiens. What is meant by these concepts in data collection and data analysis? Are the implicit definitions defensible? Moreover, how does recent work on archaic hominins change our understanding of 'subspecies' and how to draw boundaries across and within species? And what role do vernacular terms such as 'tribe' (TallBear, 2008) or the ordinary concept of 'race' (Hardimon, 2003, 2013) play in our conceptualizations of race? Do these concepts imply some kind of (imagined) purity, or is 'multi-raciality' always already an accepted possibility $(2.9 \%$ of the USA population, United States Census Bureau, 2012)? What are the normative and technical consequences of using potential euphemisms for the term 'race'?

(2) Mathematical Modeling of Human History and Population Structure: What are the aims and methods of various mathematical models of human populations? Which sorts of genetic distance measures (e.g., Nei, 1987; Reynolds, Weir, \& Cockerham, 1983) and algorithmic procedures (e.g., Felsenstein, 2004; Nielsen, Mountain, Huelsenbeck, \& Slatkin, 1998) can and should be used for inferring the human family tree (e.g., Cavalli-Sforza, Menozzi, \& Piazza, 1994; Gannett \& Griesemer, 2004)? How do we make sense of a putative controversy (the "Lewontin-Edwards conundrum") between, on the one hand, those who emphasize Lewontin's well-known 1972 result that only approximately 5\% of all genetic difference is found among racial groups (e.g., Brown \& Armelagos, 2001; Kaplan \& Winther, 2013, 2014; Lewontin, 1972; Winther, 2014), and the recent results that human populations cluster nicely, and that individuals can be reliably assigned to clusters, given enough loci (e.g., Huelsenbeck \& Andolfatto, 2007; Rosenberg et al., 2002; see also Edwards, 2003)? In short, which assumptions go into modeling methods (e.g., Winther, 2006) that (i) assess genetic variance within and among pre-defined groups (ii) aggregate sampled individuals into robust a posteriori clusters, or (iii) infer our history as a species, including archaic hominins such as Neanderthals and Denisovans (e.g., Liang \& Nielsen, 2011; Winther, 2011)?

(3) Data and Technologies of Human Genomics: For data collection, biologists must make assumptions about the number of sampled populations, population delineation, ways of sampling individuals from particular populations (e.g., Weiss \& Fullerton, 2005), statistical standardization of numbers and distributions of individuals in different populations, and even about potential functional relations among loci, only some of which may be sampled (e.g., Nielsen, 2009). Subsequent data analyses may be seen as confirming or disconfirming initial assumptions. Moreover, assumptions about the capabilities and limits of technologies of sequencing and biomedicine are also at play (e.g., Fujimura \& Rajagopalan, 2011; TallBear, 2008). What do genomic biologists and lab technicians concerned with data management and technologies actually say about how they collect, share, and interpret relevant data?

(4) Biological Reality of Race: Do human races exist, and if so in which sense of the term? Can and should genomics tell us whether races are really real, potentially through mathematical machinery that simply identifies abstract populations as units of evolution? Or does genomics-and the 
very concept of 'race' itself-perhaps already contain assumptions permeated with our social racialized ontology, thereby making claims about the objective existence of races difficult to justify? Some philosophers argue for a social constructivist account of race (e.g., Appiah, 2006; Haslanger, 2008); others for a pragmatic or deflationist account (e.g., Gannett, 2007; Hardimon, 2013); still others for a conventionalist account of bio-genomic 'race' (Kaplan \& Winther, 2013; Winther \& Kaplan, 2013; see Mills, 1988 for a useful albeit slightly incomplete taxonomy of positions). The concept 'race' is linked with the philosophical literature on natural kinds (e.g., Hacking, 2005; Kitcher, 2007), in part because of interest in whether inferences about medical conditions and treatments (e.g., Risch, Buchard, Ziv, \& Tang, 2002; Taylor et al., 2004; Wade, 2004, 2014), or about IQ and cognitive capacities (e.g., Evans et al., 2005; see Richardson, 2011 for a critique), can be underwritten using race. To what extent is race real, and which inferences about the body and mind could it ground?

(5) Racialized Selves in a Global Context: How is the self impacted by genomic practices? How do the aims of genomic research inform the racial identifications that are assumed in, and result from, data management and modeling practices? There are "looping effects" (Hacking, 2007) among (i) experts, (ii) academic witnesses, (iii) participants (and their genomes) from indigenous populations (e.g., Yanomami, Japanese, and Danes-basically any non-admixed population), (iv) self-conceptualizations, (v) institutions, and (vi) the racialized classifications themselves. An investigation of these looping effects makes explicit the making, unmaking, and realignment of 'race' in our PostGenomic "Biology 2.0" Age (see article in The Economist), at both the individual and institutional level. Identifications empower. They also make us vulnerable.

(6) Pragmatic Consequences of 'Race Talk' among Biologists: When biologists talk about race, continental origin, or clusters representing human variation, what are the social consequences? How is biological discourse about human diversity reflected in science journalism and science education? Does the use of concepts like population structure reinforce lay beliefs about putative genetically-based group differences on human traits like intelligence? If biological race talk may have harmful pragmatic consequences, how should biologists respond? The stances of biologists on race have biomedical and public health implications (e.g. Bergstrom, Garratt, \& Sheehan-Connor, 2009; Risch et al., 2002), and they are passed on to the public via media outlets, often in forms over which they have limited control (Rachul, Ouellette, \& Caulfield, 2011). Reporting on race can influence the ways laypeople make sense of new information about group differences (Condit \& Bates, 2005). Given these varied considerations, how can biologists thoughtfully proceed with their research and dissemination practices?

\section{Acknowledgements}

Our multi-year "Philosophy in a Multicultural Context" Research Cluster was institutionally supported by the UC Santa Cruz (UCSC) Institute for Humanities Research (IHR), and led by Winther. Additional support for the 2013-2014 theme "Genomics and Philosophy of Race" was provided by the Philosophy Department at UC Santa Cruz, the Computational, Evolutionary, and Human Genomics Center at Stanford University, and Science and Technology Studies at UC Davis. Concerning support from individuals, the three editors of this special issue would like to thank
Michael "Doc" Edge in particular for outstanding and singular moral, intellectual, and administrative support throughout the year. Carlos Andrés Barragán and James Griesemer provided invaluable assistance with the UC Davis workshop and participated actively throughout the year. Evin Guy, Courtney Mahaney, Irena Polic, and Nathaniel Deutsch of IHR provided guidance, both ongoing and with respect to the UC Santa Cruz conference. Finally, we are grateful to all cluster participants and to the public present at the Stanford and UC Davis workshops and the UCSC conference. Details of cluster participants and activities can be found here: http://ihr.ucsc.edu/portfolio/philosophy-in-a-multicultural-context/

\section{References}

Appiah, K. A. (2006). How to decide if races exist. Proceedings of the Aristotelian Society, 106, 363-380.

Bergstrom, T. C., Garratt, R., \& Sheehan-Connor, D. (2009). Once chance in a million: Altruism and the bone marrow registry. American Economic Review, 9, 1309-1334.

Biology 2.0. (2010). A special report on the human genome. The Economist, 17 June. http://www.economist.com/node/16349358.

Brown, R. A., \& Armelagos, G. J. (2001). Apportionment of racial diversity: A review. Evolutionary Anthropology, 10, 34-40.

Cavalli-Sforza, L. L., Menozzi, P., \& Piazza, A. (1994). The history and geography of human genes. Princeton, NJ: Princeton University Press.

Condit, C., \& Bates, B. (2005). How lay people respond to messages about genetics, health, and race. Clinical Genetics, 68, 97-105.

Edwards, A. W. F. (2003). Human genetic diversity: Lewontin's fallacy. BioEssays, 25 , $798-801$.

Evans, P. D., Gilbert, S. L., Mekel-Bobrov, N., Vallender, E. J., Anderson, J. R., Tishkoff, S. A., et al. (2005). Microcephalin, a gene regulating brain size, continues to evolve adaptively in humans. Science, 309, 1717-1720.

Felsenstein, J. (2004). Inferring phylogenies. Sunderland, MA: Sinauer.

Fujimura, J. H., \& Rajagopalan, R. (2011). Different differences: The use of 'genetic ancestry' versus race in biomedical human genetic research. Social Studies of Science, 41, 5-30.

Gannett, L. (2007). Group categories in pharmacogenetics research. Philosophy of Science, 72, 1232-1247.

Gannett, L., \& Griesemer, J. (2004). The ABO blood groups: Mapping the history and geography of genes in Homo sapiens. In H.-J. Rheinberger, \& J.-P. Gaudilliere (Eds.), Classical genetic research and its legacy. The mapping cultures of twentiethcentury genetics (pp. 119-172). New York: Routledge.

Gould, S. J. (1978). Morton's ranking of races by cranial capacity: Unconscious manipulation of data may be a scientific norm. Science, 200, 503-509.

Hacking, I. (2005). Why race still matters. Daedalus, 134, 102-116.

Hacking, I. (2007). Kinds of people: Moving targets. Proceedings of the British Academy, 151, 285-318.

Hardimon, M. O. (2003). The ordinary concept of race. Journal of Philosophy, 100, $437-455$.

Hardimon, M. O. (2013). Race concepts in medicine. The Journal of Medicine and Philosophy, 38, 6-31.

Haslanger, S. (2008). A social constructionist analysis of race. In B. A. Koenig, S. S.-J. Lee, \& S. S. Richardson (Eds.), Revisiting race in a genomic age (pp. 56-69). New Brunswick, NJ: Rutgers University Press.

Huelsenbeck, J. P., \& Andolfatto, P. (2007). Inference of population structure under a Dirichlet process. Genetics, 175, 1787-1802.

Kaplan, J. M., \& Winther, R. G. (2013). Prisoners of abstraction? Genetic diversity, differentiation, and heterozygosity, and the very concept of "race." Biological Theory, 7, 401-412.

Kaplan, J. M., \& Winther, R. G. (2014). Realism, antirealism, and conventionalism about race. Philosophy of Science, 81, 1039-1052.

Kitcher, P. (2007). Does "race" have a future? Philosophy and Public Affairs, 35, 293-317.

Lewis, J. E., DeGusta, D., Meyer, M. R., Monge, J. M., Mann, A. E., \& Holloway, R. L. (2011). The mismeasure of science: Stephen Jay Gould versus Samuel George Morton on skulls and bias. Plos Biology, 9, e1001071. http://dx.doi.org/10.1371/ journal.pbio.1001071.

Lewontin, R. C. (1972). Apportionment of human diversity. Evolutionary Biology, 6, $381-398$.

Liang, M., \& Nielsen, R. (2011). Q\&A: Who is H. sapiens really, and how do we know? BMC Biology, 9, 20. http://www.biomedcentral.com/1741-7007/9/20.

Mills, C. W. (1988). But what are you really? The metaphysics of race. In C. W. Mills (Ed.), Blackness visible: Essays on philosophy and race (pp. 41-66). Ithaca, NY: Cornell University Press.

Millstein, R. L. (2009). Populations as individuals. Biological Theory, 4, 267-273.

Millstein, R. L. (2010). The concepts of population and metapopulation in evolutionary biology and ecology. In M. A. Bell, D. J. Futuyma, W. F. Eanes, \& J. S. Levinton (Eds.), Evolution since Darwin: The first 150 years (pp. 61-86). Sunderland, MA: Sinauer.

Morton, S. G. (1849). Catalogue of skulls of man and the inferior animals (3rd ed.). Philadelphia: Merrihew and Thompson Printers. 
Nei, M. (1987). Molecular evolutionary genetics. New York: Columbia University Press. Nielsen, R. (2009). Adaptationism - 30 years after Gould and Lewontin. Evolution, 63, 2487-2490.

Nielsen, R., Mountain, J. L., Huelsenbeck, J. P., \& Slatkin, M. (1998). Maximumlikelihood estimation of population divergence times and population phylogeny in models without mutation. Evolution, 52, 669-677.

Rachul, C., Ouellette, C., \& Caulfield, T. (2011). Tracing the use and source of racial terminology in representations of genetic research. Genetics in Medicine, 13, $314-319$.

Reardon, J. (2005). Race to the finish. Identity and governance in an age of genomics. Princeton, NJ: Princeton University Press.

Reynolds, J., Weir, B. S., \& Cockerham, C. C. (1983). Estimation of the coancestry coefficient: Basis for a short-term genetic distance. Genetics, 105, 767-799.

Richardson, S. S. (2011). Race and IQ in the postgenomic age: The microcephaly case. BioSocieties, 6, 420-446.

Risch, N., Buchard, E., Ziv, E., \& Tang, H. (2002). Categorization of humans in biomedical research: Genes, race and disease. Genome Biology, 3, 1-12.

Rosenberg, N. A., Pritchard, J. K., Weber, J. L., Cann, H. M., Kidd, K. K., Zhivotovsky, L. A., et al. (2002). Genetic structure of human populations. Science, 298, 2381-2385.

TallBear, K. (2008). Native-American-DNA.com: In search of native American race and tribe. In B. A. Koenig, S. S.-J. Lee, \& S. S. Richardson (Eds.), Revisiting race in a genomic age (pp. 235-252). New Brunswick, NJ: Rutgers University Press.
Taylor, A. L., Ziesche, S., Yancy, C., Carson, P., D’Agostino, R., Jr, Ferdinand, K., et al. (2004). Combination of isosorbide dinitrate and hydralazine in blacks with heart failure. New England Journal of Medicine, 351, 2049-2057.

UNESCO. (1952). The race concept: Results of an inquiry. Paris: UNESCO.

United States Census Bureau. (2012). The two or more races population: 2010. http:// www.census.gov/prod/cen2010/briefs/c2010br-13.pdf.

Wade, N. (2014). A troublesome inheritance. Genes, race and human history. New York: Penguin.

Weiss, K. M., \& Fullerton, S. M. (2005). Racing around, getting nowhere. Evolutionary Anthropology, 14, 165-169.

Winther, R. G. (2006). Fisherian and Wrightian perspectives in evolutionary genetics and model-mediated imposition of theoretical assumptions. Journal of Theoretical Biology, 240, 218-232.

Winther, R. G. (2011). ¿La cosificación genética de la 'raza’? Un análisis crítico. In C. López Beltrán (Ed.), Genes (E) mestizos. Genómica y raza en la biomedicina mexicana (pp. 237-258). Mexico City: Ficticia-UNAM (in Spanish)

Winther, R. G. (2014). The genetic reification of 'race'? A story of two mathematical methods. Critical Philosophy of Race, 2, 204-223.

Winther, R. G., \& Kaplan, J. M. (2013). Ontologies and politics of biogenomic 'race' Theoria. A Journal of Social and Political Theory (South Africa), 60, 54-80.

Wade, N. (2004, November 14). Race-based medicine continued... New York Times. http://www.nytimes.com/2004/11/14/weekinreview/14nick.html. 